\title{
A stochastic model to study the control of grazing systems
}

\author{
L.G. BARIONI, C.K. DAKE and W.J. PARKER \\ Department of Agribusiness \& Resource Management, \\ Massey University, Palmerston North
}

\begin{abstract}
Most modelling research into grazing management has focused on planning. However, if target outcomes for pastures, animals and profit are to be realised, planning and control must be closely linked. Control is required if actual outcomes are likely to deviate from those planned. This may be because of: variability in uncontrollable variables (e.g., the weather); imprecision in implementation (including timeliness); inaccurate measurement of outcomes (i.e., sensor errors); and errors in prediction during the planning process. A dynamic grazing system model was used with a genetic optimising algorithm to simulate the outcomes for different control strategies for a sheep farmlet. The optimum control sequencing for pasture allowance, nitrogen application, lamb drafting weight and supplementation was investigated. Optimum pasture cover levels were similar to those recommended to farmers, except for winter when higher allowances were suggested. Sensor errors for pasture measurement were shown not to have a significant financial cost to farmers if recommended measurement techniques are closely followed.
\end{abstract}

Keywords: grazing control, grazing management, grazing system model, pasture measurement, system optimisation

\section{Introduction}

Several decision support models have been developed to assist managers of pastoral livestock production systems in New Zealand and Australia (e.g., Marshall et al. 1991; Finlayson et al. 1995; Freer et al. 1997). The main application of these models has been to assist strategic planning. In practice, however, strategic plans are implemented under circumstances with production risk, and consequently deviations from the strategic plan may require changes to management in order to correct for unsatisfactory performance. There is therefore a need to consider the control aspects of grazing systems through actions like restricting herbage allowance, applying nitrogen and adjusting stocking rate. Variation in pasture growth rates (i.e., uncontrollable variables), errors in pasture measurement (i.e., sensor errors) and imprecision in implementing plans can all lead to key production variables, such as pasture cover and animal liveweight, being different to that which was predicted (Athans 1972). These sources of uncertainty and variability may affect system performance by either leading to control errors (i.e., taking sub-optimal decisions based on a wrong measurement or prediction) or affecting the dynamics of the system and lead to a sub-optimal state (as may be caused by uncontrollable variables such as weather).

Cacho \& Bywater (1994) and Pleasants et al. (1997) demonstrated that the asymmetry of a system response to a stochastic variable may lead to its mean being different from that generated by a deterministic model which uses the mean of that stochastic variable. The intake and productivity response of grazing animals to herbage allowance, sward height, herbage mass or leaf area are typically non-linear and asymmetrical (McCall 1984; Johnson \& Parsons 1985), and this raises the question "To what extent do errors in herbage mass prediction affect the efficiency of a grazing system?" To study this question and other aspects of the control of grazing systems, a dynamic simulation model coupled to an optimisation algorithm was constructed (Barioni 1997). In this paper the model's use is exemplified by an optimisation experiment for grazing management and by testing the effects of pre-grazing measurement errors on system performance.

\section{Model design}

The iconic simulation package Extend ${ }^{\mathrm{TM}}$, was used to construct a model of a pastoral sheep enterprise (Barioni 1997). The model is event-driven; events correspond to the shifting of the animals from one paddock to another. Each paddock is simulated as a single entity with inherent attributes such as grazing area, sward characteristics, and potential for pasture production. The rotation sequence for grazing is determined by always allocating the flock (of ewes, flock replacements or lambs) to the paddock with the greatest pasture mass which, according to Woodward et al. (1995), is almost always the best strategy for pasture growth and its utilisation in multipaddock systems. 
Herbage mass is divided into three fractions: leaf, stem and dead. Pasture growth and senescence rates for individual paddocks are calculated from pasture leaf mass, and net pasture growth rate equals total growth less senescence. The Micherlich-type function suggested by Thornley \& Johnson (1990) is used to relate leaf mass to total pasture growth. Senescence is assumed to increase linearly with herbage mass. Deterministic or stochastic pasture growth rate data can be generated. Pasture responses to nitrogen are estimated for each month of the year and moderated by the farm's location using data presented by O'Connor (1982). The lagged response to nitrogen, an inverse function of the total nitrogen response (O'Connor 1982), usually occurs over a period of 3 to 10 weeks.

Animal performance of the sheep classes is calculated using average attributes for ewes, ewe hoggets and rams, but lambs are simulated individually. The performance of each lamb is affected by its birth date and sex, and this information is generated by a submodel for MA ewe and ewe hogget reproduction. The potential herbage intake of the sheep is defined by rumen fill and the physiological energy demand following the procedures of Finlayson et al. (1995). The effect of herbage availability on intake is based on pre-grazing green herbage mass and green herbage allowance according to McCall (1984). The grazing time spent in each paddock is based on a linear interpolation of userdefined herbage allowances for each month of the year. The proportion of leaf, stem and dead material in the diet is calculated according to the proportion of each of these fractions in the sward and herbage availability. If animals are supplemented they consume all of the material offered. This affects pasture intake by decreasing the physiological energy demand and utilising rumen space otherwise taken up by grazed pasture. The substitution rate is calculated indirectly from these limits.

The partitioning of nutrients by animals is estimated from the ratio between energy intake and energy demand in an animal growth sub-model. This is driven by the DNA, protein and fat content of the animal as described by Finlayson et al. (1995). As noted earlier, growth is simulated individually for lambs, but average liveweights are used for other sheep classes. Lambs are drafted for sale and graded according to user-defined monthly threshold drafting weights. Carcass weight and fatness
(GR) are generated from the liveweight and sex of individuals lambs using the equations of Garrick et al. (1986). Not all lambs are sold; the number of replacements can be specified and these are transferred into the ewe hogget mob and then onto the "pool" for ewes. The date for, and number of, empty and cull ewe sales are also user-defined. Model output was validated against three experimental data sets as described by Barioni (1997). This indicated a good fit of predicted versus measured values for lamb liveweight gain and digestibility of pasture consumed but ewe liveweight was slightly underestimated.

\section{Experimental design}

The model was used to evaluate the effect of errors in predicting pre-grazing mass on the dynamics of pasture cover and the annual gross margin of a sheep system. The experiment was conducted in two stages: first, the genetic algorithm was used to search for the optimum deterministic control sequence for the system, and second, variability was introduced to the measurement of pre-grazing herbage mass. Both parts of the experiment were performed using a theoretical 8 ha farmlet with 8 paddocks of equal size and pasture production potential. The optimisation was run for 12 months from 1 March. A mob of 140 ewes (17.5 ewes/ ha), at an initial liveweight of $55 \mathrm{~kg}$, was grazed on a starting pasture cover of $1500 \mathrm{~kg} \mathrm{DM} / \mathrm{ha}$. Inputted pasture growth rates were typical of those recorded at the Massey University No. 4 Dairy Unit (Table 1). A lambing pattern was generated for 105 ewes and 35 ewe hoggets using the reproduction sub-model. This produced a $130 \%$ lambing. The lambing pattern was stored and used as required during the optimisation.

A genetic algorithm (Goldberg 1989) was implemented to optimise the control variables in the model for deterministic runs. The optimum control sequence was identified for herbage allowance, nitrogen application (restricted to April and August applications), supplementation during winter and lamb drafting weight (Table 2). The algorithm was run for 20 generations with 35 individuals per generation requiring 700 iterations. The crossover probability and mutation probability for the algorithm were assigned to 0.6 and 0.033 , respectively. A penalty function was introduced

Table 1 Daily net pasture growth rates (kg/ha/day) for the Massey University \& No. 4 Dairy Farm, used in the simulations.

\begin{tabular}{|c|c|c|c|c|c|c|c|c|c|c|c|c|}
\hline & Jan & Feb & Mar & Apr & May & Jun & Jul & Aug & Sep & $0 \mathrm{ct}$ & Nov & $\mathrm{Dec}$ \\
\hline Mean $^{1}$ & 24 & 23 & 21 & 23 & 29 & 22 & 17 & 27 & 40 & 50 & 47 & 36 \\
\hline CV\% & 50.4 & 47 & 42.8 & 35.3 & 38.0 & 45.7 & 42.1 & 28.6 & 36.5 & 24.1 & 31.7 & 32.8 \\
\hline
\end{tabular}

For each step of the simulation, pasture growth rate was interpolated linearly assuming the above growth rates on the $15^{\text {th }}$ of each month. 
to ensure that pasture cover at the end of the period was not less than the initial cover. Direct costs (NZ\$226.61/ha), wool $(\$ 5 / \mathrm{kg}$ clean $)$, nitrogen $(\$ 1.30 / \mathrm{kg}$ $\mathrm{N}$ applied) and hay $(\$ 0.23 / \mathrm{kg} \mathrm{DM}$ consumed) were inputted. Lamb schedules were those published on 27 April by the New Zealand Farmer (1997). The seasonal premiums assumed on the base lamb schedule price are shown in Figure 1. Carcasses were classified according to the carcass weight/GR grid specified by Kirton (1989).

The effect of measurement errors was tested by running four simulations each over 10 years for the system with and without the inclusion of sensor error and using the optimal sequence for deterministic control. The sensor error was introduced by calculating the grazing time for a randomly "measured" pre-grazing pasture generated from a normal distribution with the mean equal to the actual mean and a coefficient of variation of either $20 \%$ or $40 \%$. Coefficients of variation from 13 to $16 \%$ are suggested by L'Hullier \& Thomson (1988) for the rising plate meter, pasture probe or visual assessment.

\section{Results and discussion}

The pasture allowances suggested by the optimisation (Table 3) for sheep are reasonably consistent with the
Table 2 Parameters of the control variables used in the optimisation of the sheep farming system.

\begin{tabular}{llccc}
\hline \multicolumn{1}{c}{ Variable } & & Unit & Range & Increment \\
\hline Pasture allowance & (Jan-Jun) & $\mathrm{kg} \mathrm{DM} / \mathrm{kg} \mathrm{potential} \mathrm{DMI}$ & $0.5-2.75$ & 0.15 \\
& (Jul-Dec) & " & $1.0-4.75$ & 0.25 \\
Nitrogen application & (per month) & $\mathrm{kg} \mathrm{N} / \mathrm{ha}$ & $0-87.5$ & 12.5 \\
Lamb drafting weight & & $\mathrm{kg} \mathrm{liveweight}$ & $26-41$ & 1 \\
Supplementation & (May-Jun) & $\mathrm{kg} \mathrm{DM} /$ sheep/day & $0-0.7$ & 0.1 \\
\hline
\end{tabular}

Figure 1 Seasonal premiums assumed to be paid on lamb carcasses (c) $\mathrm{kg}$ ) for the optimisation exercise.

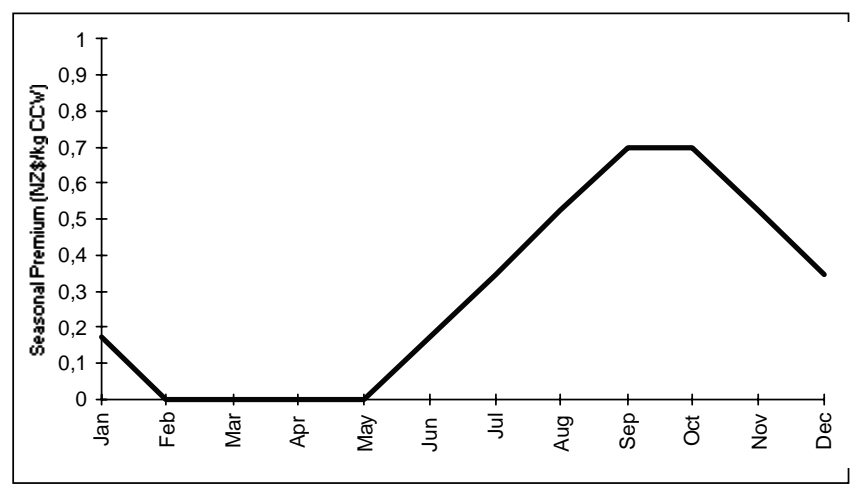

recommendations of Rattray et al. (1987), except for the relatively high herbage allowances and residual covers in the winter. High allowances may reflect the stocking rate used in the experiment as well as the positive responses of pasture growth to leaf area index

Table 3 The optimum solution for the 8 ha farmlet simulation at a stocking rate of $17.5 \mathrm{ewes} / \mathrm{ha}$, lambing $130 \%$ and mating from 11 March to 21 May.

\begin{tabular}{|c|c|c|c|c|c|c|c|}
\hline \multicolumn{8}{|c|}{ Gross Margin: NZ\$587.47/ha } \\
\hline Month & $\begin{array}{c}\text { Allowance } \\
\text { per potential } \\
\text { intake }^{1}\end{array}$ & $\begin{array}{l}\text { Nitrogen } \\
\text { applied } \\
\text { (kg N/ha) }\end{array}$ & $\begin{array}{l}\text { Supplement } \\
\text { used } \\
\text { (kg DM) }\end{array}$ & $\begin{array}{c}\text { Lamb } \\
\text { drafting weight }{ }^{2} \\
(\mathrm{~kg})\end{array}$ & $\begin{array}{c}\text { Allowance }^{3} \\
\text { (kg DM/ ssu /day) }\end{array}$ & $\begin{array}{l}\text { Post-grazing } \\
\text { (kg DM /ha) }\end{array}$ & $\begin{array}{c}\text { Pasture } \\
\text { cover } \\
\text { (kg DM/ha) }\end{array}$ \\
\hline Mar & 2.15 & 0 & 0 & - & 2.67 & 1042 & 1461 \\
\hline Apr & 2.00 & 12.5 & 0 & - & 2.17 & 994 & 1433 \\
\hline May & 1.10 & 0 & 0 & - & 1.56 & 1130 & 1579 \\
\hline Jun & 2.75 & 0 & 0 & - & 3.11 & 1155 & 1470 \\
\hline Jul & 2.30 & 0 & 0 & - & 2.27 & 887 & 1204 \\
\hline Aug & 1.25 & 50 & 0 & - & 1.60 & 914 & 1291 \\
\hline Sep & 2.00 & 0 & 0 & - & 2.78 & 1303 & 1753 \\
\hline Oct & 2.00 & 0 & 0 & 35 & 3.53 & 1712 & 2127 \\
\hline Nov & 3.50 & 0 & 0 & 35 & 5.00 & 1881 & 2259 \\
\hline Dec & 3.00 & 0 & 0 & 37 & 3.46 & 1664 & 2167 \\
\hline Jan & 1.55 & 0 & 0 & 33 & 2.28 & 1488 & 1986 \\
\hline Feb & 2.75 & 0 & 0 & - & 3.41 & 1334 & 1708 \\
\hline \multicolumn{8}{|c|}{1 Calculated as the ratio between the total herbage mass offered daily and the potential intake calculated by the model (this is the control } \\
\hline \multicolumn{8}{|c|}{2 Threshold liveweight for lamb drafting. } \\
\hline \multicolumn{8}{|c|}{3 Sheep stock units were calculated relative to a standard liveweight of $55 \mathrm{~kg}$. } \\
\hline
\end{tabular}


and of ewe milk production to body condition, in the model. These relationships require further study because in practice most farmers graze ewes much more tightly during the winter-early spring than the model suggests in order to control the level of pasture intake. The model suggests that the farmers' strategy is not without cost in terms of the system's performance. Also, nitrogen was included quite generously in the optimisation relative to normal practice (Parker et al. 1994). This reflects the high (1997) lamb prices compared to the cost of Nboosted pasture. One limitation of the model, however, is that lambs and ewes are grazed together throughout the year and distinct pasture management for these sheep classes cannot be simulated.

Introduction of measurement error at a CV of $40 \%$ was shown to cause significant changes in the monthly pasture cover compared with the situation with no measurement errors (Figure 2). On the other hand a $20 \%$ CV would not affect simulated estimates of future pasture cover. Thus, grazing systems seems to have a propensity to return to a dynamic equilibrium between intake and pasture growth rate in a manner similar to that demonstrated by Noy-Meir (1975) for the static case. Also, subsequent errors from paddock to paddock can have a compensatory effect (i.e., upside errors can follow downside errors and so on). For this analysis no feedback control by the farmer was assumed because the relatively low precision with which they can estimate post-grazing pasture mass (L'Hullier \& Thomson 1988) means that small deviations are unlikely to be noticed early enough to achieve efficient control. Although large differences in pre-grazing pasture mass may be detected in time to allow efficient control, variation in average pasture cover owing to sensor error in this simulation was small as illustrated in Table 4, indicating that little difference to the outcomes would have been achieved even if efficient feedback control had been implemented. Little is known about how efficient farmers are in achieving control in pasture management and this is a topic which deserves further study.

Figure 2 Average monthly pasture cover for three levels of sensor error without pasture growth rate variability.

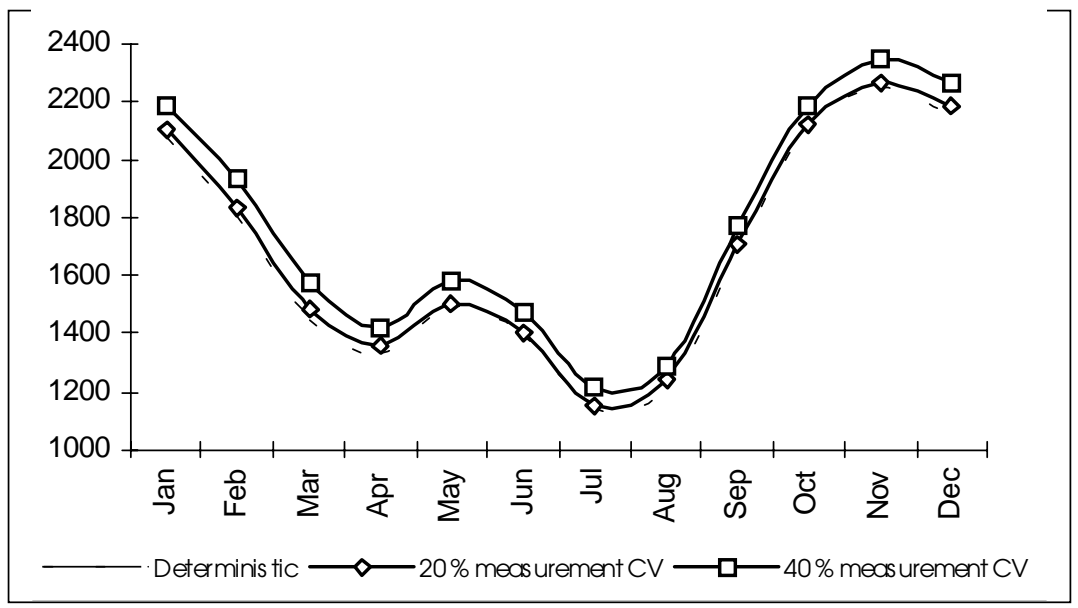

Table 4 Variation in the estimates of average pasture cover in each month for three levels of measurement error.

\begin{tabular}{llllllllllllll}
\hline $\begin{array}{c}\text { Measurement } \\
\text { CV }\end{array}$ & & Jan & Feb & Mar & Apr & May & Jun & Jul & Aug & Sep & Oct & Nov & Dec \\
\hline $0 \%$ & Mean & 2081 & 1806 & 1446 & 1330 & 1495 & 1393 & 1146 & 1216 & 1682 & 2108 & 2243 & 2156 \\
& Max & 2090 & 1823 & 1462 & 1340 & 1504 & 1399 & 1151 & 1220 & 1688 & 2113 & 2245 & 2157 \\
& Min & 2075 & 1798 & 1440 & 1318 & 1482 & 1381 & 1135 & 1211 & 1675 & 2100 & 2238 & 2148 \\
$20 \%$ & Mean & 2101 & 1837 & 1484 & 1356 & 1506 & 1403 & 1156 & 1240 & 1713 & 2123 & 2266 & 2180 \\
& Max & 2156 & 1908 & 1558 & 1411 & 1566 & 1448 & 1195 & 1317 & 1820 & 2165 & 2293 & 2210 \\
& Min & 2043 & 1769 & 1412 & 1293 & 1463 & 1359 & 1129 & 1183 & 1645 & 2047 & 2214 & 2140 \\
$40 \%$ & Mean & 2189 & 1929 & 1571 & 1426 & 1583 & 1475 & 1216 & 1289 & 1775 & 2186 & 2345 & 2264 \\
& Max & 2330 & 2105 & 1739 & 1551 & 1683 & 1572 & 1287 & 1363 & 1919 & 2272 & 2437 & 2355 \\
& Min & 2096 & 1808 & 1472 & 1331 & 1432 & 1403 & 1152 & 1216 & 1626 & 2091 & 2273 & 2180 \\
\hline
\end{tabular}


Figure 3 Effect of measurement error on the gross margin (GM) of the simulated sheep system including or not pasture growth variability. Vertical bars indicate the standard error of the mean. (The regression of GM on CV is: $y=587.5+0.560 \mathrm{CV}+$ $0.056 \mathrm{CV}^{2}, \mathrm{r}^{2}=0.658, \mathrm{P}<0.05$.)

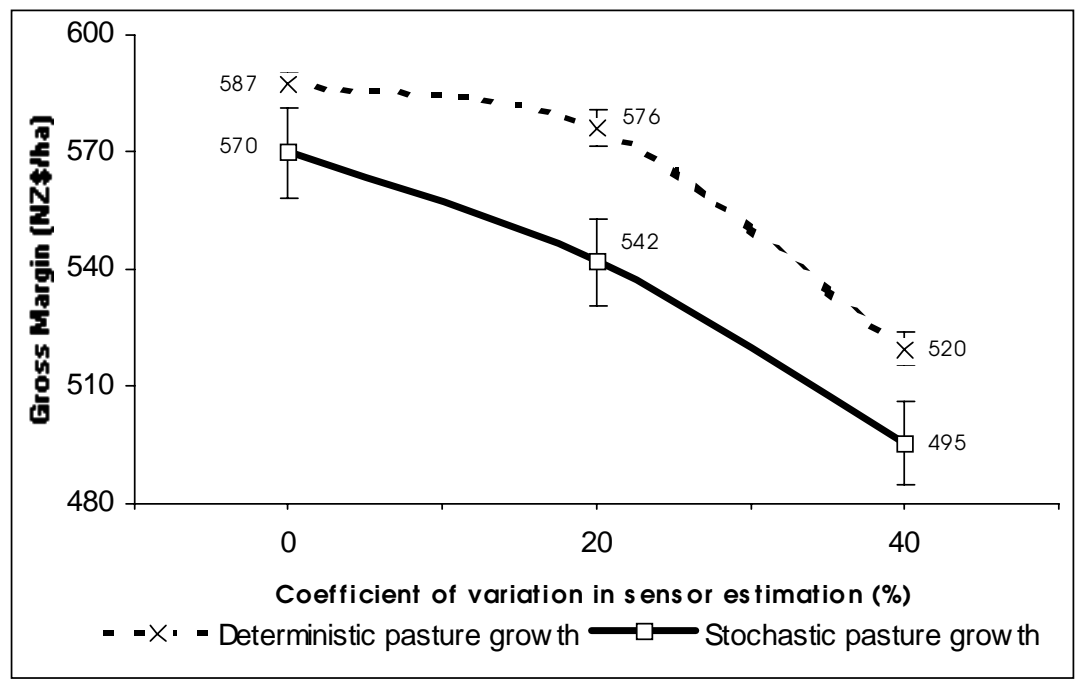

Gross margins for the system were significantly $(\mathrm{P}<0.05)$ affected by measurement errors at the level of $40 \% \mathrm{CV}$, whether or not pasture growth variability was included (Figure 3, Table 5). A measurement error of $20 \%$ CV decreased the gross margins slightly with or without pasture growth variability, but the effect was not statistically significant $(\mathrm{P}=0.086)$ when variability in growth was included. The simulation results indicate that providing farmers exercise care with their pasture measurement, and in doing so achieve or exceed the levels of accuracy and repeatability that L'Hullier \& Thomson (1988) suggest, the control of grazing at the operational level should be close to the optimum. Of course this assumes that other aspects of the farmer's grazing management are of a high standard. If this is not the case, and errors such as those simulated for a $40 \% \mathrm{CV}$ occur, the farmer will pay a significant price (e.g., NZ\$ 74.31/ha for variable pasture growth in the simulation reported here).

\section{Conclusions}

Simulation models can be used to develop optimum plans and control sequences for specific pastoral systems, including those for expected prices, flock-herd composition and seasonal growth patterns. However, the efficacy of these targets depends on both the accuracy of the system simulation and the efficiency of the algorithm in finding the optimum for that system. More research is necessary in this area. Optimisation
Table 5 The frequency distribution of gross margins (NZ\$/ha) for different levels of pasture measurement error.

\begin{tabular}{lccc}
\hline GM range & $-1 \%$ & $\begin{array}{r}\text { Coefficient of Variation } \\
\text { 20\% }\end{array}$ & $40 \%$ \\
\hline$<500$ & 0 & 0 & 2 \\
$500-519$ & 0 & 1 & 2 \\
$520-539$ & 0 & 2 & 9 \\
$540-559$ & 0 & 3 & 10 \\
$560-579$ & 10 & 6 & 5 \\
$580-599$ & 13 & 13 & 0 \\
$600-619$ & 4 & 2 & 0 \\
$>620$ & 1 & 1 & 0 \\
\hline
\end{tabular}

algorithms are pre-requisites to the development of feedback controllers and may therefore be helpful for developing heuristic rules for control which are less demanding computationally (the simulation reported in Table 2 took 17 hours to run on a Pentium 75 computer).

The model outputs show that measurement errors can lead to sub-optimal decisions and higher control costs. However, the performance of pastoral systems seem to be tolerant of some errors in pre-grazing pasture mass estimation, providing there is no bias in the sensor used (i.e., the mean of the sensor's estimations are equal to the actual mean), but profitability can be noticeably decreased if measurement errors increase beyond $20 \% \mathrm{CV}$. The analysis reported here suggests low gains in system performance are to be expected 
from improving the accuracy of measuring pre-grazing herbage mass beyond the level provided by the measurement techniques currently applied on-farm. This assumes that bias in measurement is minimised by using the correct regression equation for pasture meters or probes, and by calibrating visual assessments of pasture mass. Failure to measure pastures accurately in order to control the performance of pasture systems may have a significant cost to farmers.

\section{REFERENCES}

Athans, M. 1972. The discrete time linear-quadraticgaussian stochastic control problem. Annals of economic and social measurement 1: 449-491.

Barioni, L.G. 1997. A dynamic simulation model for planning and controlling grazing systems. Unpublished MApplSc thesis. Massey University.

Cacho, O.J.; Bywater, A.C. 1994. Use of a grazing model to study management and risk. Proceedings of the New Zealand Society of Animal Production 54: 377-373

Finlayson, J.D.; Cacho, O.J.; Bywater, A.C. 1995. A simulation model of grazing sheep: 1 . Animal growth and intake. Agricultural systems 48: 1-25.

Freer, M.; Moore, A.D.; Donnelly, J.R. 1997. GRAZPLAN: Decision Support Systems for Australian grazing enterprises - II. The animal biology model for feed intake, production and reproduction and the GrazFeed DSS. Agricultural systems 54: 77-126.

Garrick, D.J.; Purchas, R.W.; Morris, S.T. 1986. Consideration of alternative lamb drafting strategies. Proceeding of the New Zealand Society of Animal Production 46: 49-54.

Goldberg, D.E. 1989. Genetic algorithms in search, optimisation and machine learning. AddisonWesley, Reading.

Johnson, I.R.; Parsons, A.J. 1985. Use of a model to analyse the effect of continuous grazing managements on seasonal patterns of grass production. Grass and forage science 40: 449-458.

Kirton, A.H. 1989. Principles of classification and grading. pp. 143-157, In: Meat production and processing. Eds. R.W. Purchas, B.W. Butler-Hogg and A.S. Davies. New Zealand Society of Animal Production Occasional Publication no.11.

L'Huillier, P.J.; Thomson, N.A. 1988. Estimation of herbage mass in ryegrass-white clover dairy pastures. Proceedings of New Zealand Grassland Association 49: 117-122.

Marshall, P.R.; McCall, D.G.; Johns, K.L. 1991. Stockpol: A decision support model for livestock farmers. Proceeding of the New Zealand Grassland Association 53: 137-140.

McCall, D.G. 1984. A systems approach to research planning for North Island hill country. Unpublished $\mathrm{PhD}$ thesis, Massey University.

Noy-Meir, I. 1975. Stability of grazing systems: an application of predator-prey graphs. Journal of ecology 63: 459-481.

O'Connor, M.B. 1982. Nitrogen fertilisers for the production of out of season grass. pp. 65-76, In: Nitrogen fertilisers in New Zealand agriculture. Ed. Lynch, P.B. Auckland: Ray Richards Publisher.

Parker, W.J.; Dake, C.K.G.; Wright, L.; Tillman, R.W. 1994. Risk management for tactical nitrogen fertiliser applications in pastoral farming. Proceedings of the New Zealand Grassland Association 56: 223-227.

Pleasants, A.B.; Wake, G.C.; McCall, D.G.; Watt, S.D. 1997. Modelling pasture mass through time in a managed grazing system subject to perturbations resulting from complexity in natural biological processes. Agricultural systems 53: 191-208.

Rattray, P.V.; Thompson, K.F.; Hawker, H.; Sumner, R.M.W. 1987. Pastures for sheep production. pp. 89-04, In: Livestock feeding on pasture. Ed. Nicol, A.M. New Zealand Society of Animal Production Occasional Publication, no. 10.

The New Zealand Farmer Markets 1997, May 27. New Zealand Farmer, p. 32.

Thornley, J.H.M.; Johnson, I.R. 1990. Plant and crop modelling: A mathematical approach to plant and crop physiology. Oxford: Clarendon Press.

Woodward, S.J.R.; Wake, G.C.; McCall, D.G. 1995. Optimal grazing of a multi-paddock system using a discrete time model. Agricultural systems 48: 119139. 